\title{
News Crawls in Local TV News: Do They Help or Hinder Information Recall and Retention
}

\author{
Brittany L. Pavolik, Mark J. Piwinsky1, Lacey A. Fulton ${ }^{2}$ \\ ${ }^{1}$ Department of Communications Media, Indiana University of Pennsylvania, Indiana, PA, USA \\ ${ }^{2}$ Department of Communication, Clarion University, Clarion, PA, USA \\ Email: B.L.Pavolik@iup.edu
}

Received 1 December 2015; accepted 26 December 2015; published 31 December 2015

Copyright (C) 2015 by authors and Scientific Research Publishing Inc.

This work is licensed under the Creative Commons Attribution International License (CC BY). http://creativecommons.org/licenses/by/4.0/

(c) (i) Open Access

\begin{abstract}
News crawls have become a common element in local television newscasts. Used as a way to provide more information and compete with content rich online news, the question is whether news crawls help or hinder immediate recall and long-term retention of information. Using a quasi-experiment, this study examines immediate recall and long-term retention for a local television newscast. A control and two treatment groups, comprised of students at a public, mid-sized university in the USA, saw one of three versions of the same newscast. The control group saw a newscast with no crawls while the treatment groups saw a version with crawls that reinforced the onscreen story or with crawls that were on different topics from the on-screen story. Considering information overload and the dual-coding hypothesis, this study also examines the impact of the textual element of the crawl as an aid or obstacle in information recall and retention. The study lends support to the dual-coding hypothesis and suggests further research is needed on its impact even when the on-screen story and textual crawl are not covering the same news item.
\end{abstract}

\section{Keywords}

News Crawls, Local TV News, Information Overload, Dual Coding

\section{Introduction}

With the availability of numerous digital and traditional news media outlets, Americans remain loyal to local television newscast as major source information. Mitchell et al. (2013) report that in terms of local news, 71\% of viewers are tuning in regularly. Local television news creates a sense of community; a sense of belonging. Woodstock (2014) characterizes this engagement as the news democracy narrative and suggests that news-viewing habits are a key factor in an individual's level of citizenship. This sense of community or belonging remains 
strong. In fact, Matsa (2015) found that local television news viewership was increasing as stations expanded their time slots into the early morning and late evening dayparts.

While local news has a regular following, heavy viewers of local news watch more cable news than local news; an average of eleven minutes more each day (Mitchell et al., 2013). With restrictive budgets and the need for advertising dollars, local stations have increasingly mimicked cable news production elements including graphics and news crawls, scrolling information at the lower third portion of the television screen to enhance the appeal of their broadcasts.

As the news democracy narrative sees the importance of informed viewers, a key question is whether these added graphic elements help or hinder the retention of information from the newscasts. Little, at present, is known about the effects of news crawls in local televised news. Research shows, however, that the audience does pay attention to the lower third of the television screen (Rodrigues et al., 2012). Further, research focusing on news crawls in national news illustrates that some types of news crawls can have a negative impact on viewer comprehension of the on-screen story.

Focusing on local news, the impact of news crawl presence and the compatibility of the information in the crawl with the on-screen story are examined for their impact on immediate recall and long-term retention. In addition, this study also examines if the presence of news crawl can influence the retention of information that is presented in the on-screen story, but not textually reinforced in the news crawl.

\section{Literature Review}

In 1948, WPIX produced the first fifteen-minute local television newscast, in New York City, utilizing the “talking head" format (Klinenberg \& Krause, 2005; Hinds, 1995). Beginning in the 1960s, stations began to differentiate their newscasts using elements such as identifiable personalities, music, b-roll, and graphics. The first text-on-screen graphic appeared in the 1980's in the form of a stock ticker (Coffrey \& Cleary, 2008). It was with the September 11th, 2001 terrorist attacks that crawls became a key element of a newscast. Due to this association, news crawls were initially identified with a sense of urgency and breaking news. Keefe-Feldman (2007) found that, over time, news crawls have evolved to regularly feed additional and often non-urgent information to the audience. In examining news crawl content, his findings were that news crawls are repetitive and typically not synchronized with the on-screen story. Rodrigues et al. (2012) note that the news crawl is more likely to grab audience attention than any other element on the screen. However, the media industry has often questioned its legitimate impact on the audience (Romano, 2002; Strauss; 2002; Consoli, 2009; Poniewozik, 2010).

\subsection{Theoretical Perspectives}

One purpose of the news crawl is to feed additional information to the viewer that is not in the on-screen story. To determine if news crawls are an aid in information recall and retention, it is necessary to begin with a brief overview of two relevant dimensions. The first concerns short- and long-term memory processing while the second examines the information overload and dual-coding perspectives. These form the basis for this study and the hypotheses.

Various scholars have examined short and long-term information processing with varying interpretations and areas of emphasis. Lindsay and Norman (1972) see information processing as a tri-fold experience beginning with initial exposure to a message. From this, the individual chooses to ignore the message, causing information decay, or encode it into the working (short-term) memory (Ruiji, 2012). Information processed to the working memory is then transferred to the long-term memory where it is stored with other accumulated knowledge until cued for recall (Fleming, et al., 2006).

The first dimension to consider is the capacity of short-term (working) and long-term memory. Cognitive load theory (Schweppe \& Rummer, 2014; Sweller et al., 1998; Chandler \& Sweller, 1991) suggests that the working memory only has a limited capacity which can be easily exceeded. Mayer (2005) points out that working memory must maintain and integrate multiple information channels, verbal and visual. In contrast, long-term memory is not seen as having the same capacity limitations. Focusing primarily on long-term retention, the Limited Capacity Model for Motivated Mediated Message Processing (LC4MP) sees three dimensions of cognitive processing, encoding, storage and retrieval, which are constant, continuous and simultaneous (Lang, 2006). Of the components of LC4MP, three are most relevant to this study: people have limited processing capacity, mediated messages contain redundancy in format to impact multiple senses, and cognition is a dynamic process 
(Fulton, 2014; Pavolik, 2015). While the limitations of working memory can inhibit what is successfully processed into long-term memory, the capacity of long-term memory is significantly greater than working memory (Schweppe \& Rummer, 2014).

Information overload and dual-coding, the second dimension, focus on what factors help or inhibit processing by the working memory and the transfer of information to long-term memory. One perspective is that an attempt to synchronously process excessive amounts of mediated messages can result in cognitive and information overload (Toffler, 1970; Jacoby et al., 1984). According to Weber, Westcott-Baker \& Anderson (2013), a high level of complexity in a message can result in cognitive overload inhibiting future message retrieval due to the high-level of resources needed for encoding, decoding and retrieval. The redundancy effect (Torcasio \& Sweller, 2009; Kalyuga et al., 1999, 2004) supports this contention arguing that removing superfluous information from a screen (the same information in different mediated forms) helps the individual to process and retain the smaller amount of information presented.

In contrast to information overload, the dual-coding hypothesis sees additional information as supportive of recall and retention. Dual-coding argues that when exposed to multimedia information, it is encoded both visually and aurally so that it is double-learned (Paivio, 1969, 1971, 1986). With multiple channels, the task of information reception can be partitioned between visual and audio channels freeing more re-sources for cognitive processing (Brunye et al., 2008; Mayer, 1997). The research of van der Molen and van der Voort $(1997,1998)$ support the dual-coding hypothesis. Essentially, the verbal and visual components of television newscasts provide dual channels to support information storage and enhance recall (van der Molen \& van der Voort, 2000). This is also seen in LC4MP (Lang, 2000; Lang et al., 2004), which sees mediated messages as comprised of redundant information presented via various channels and formats that are dynamically processed as a part of continuous interactive communication.

\subsection{News Crawls, Recall and Retention}

Studies on news crawls address both the information overload and dual-coding perspectives. News crawls, and other on-screen graphics, are production elements that newscasts use to present information, entertain the audience, and distinguish themselves from other stations (Pavolik, 2015). However, when newscasts attempt to address all three of these functions using larger amounts of stimuli, the audience can easily become overwhelmed (Grabe et al., 2000, 2003; Lang et al., 1999). As a result, viewers may be unable to correctly comprehend, store, and retrieve the presented news.

Research concerning on-screen graphics, including news crawls, shows that graphics can affect information processing but the findings are variable. Grimes (1990) found that ancillary visuals can cause an audience to misinterpret an intended message because they assume the visuals are meant to reinforce the aural messages. Joesphson and Holmes (2006) found that audience members became particularly overwhelmed when confronted with crawls on topics other than what is being presented in the on-screen story. Matsukawa et al. (2009) used reinforcing crawls to test this perspective. In a post-test only experiment, audience members produced higher immediate recall scores when exposed to crawls that reinforced the on-screen story than when exposed to a newscast with no crawls at all. Keefe-Feldman (2007) found that most crawls do not reinforce the on-screen story and that individuals exposed to these incompatible crawls were less likely to recall information presented in the newscast. A natural corollary is that news crawls containing irrelevant or unstructured information could have a negative impact on retention of the on-screen story (Hargittai et al., 2012). Bergen et al. (2005) used dual-coding to find that when confronted with media embedded with graphics, an individual will focus on the auditory elements more so than the visuals. With regard to the amount of non-reinforcing, extraneous information, Coffey and Cleary (2009) found that news networks also use crawls for self-promotion.

Demographics can also play a part in information overload (Williamson \& Eaker, 2012). A consistent pattern in the literature shows that younger audiences, regardless of their news-viewing habits, tend to be more successful than older generations at processing cluttered newscasts (Keefe-Feldman, 2007; Bergen et al., 2005). In contrast, Qihao et al. (2014) found that women under the age of 30 were more likely to become overwhelmed with information than any other demographic. Pavolik (2015), using a sample comprised of college students, found some interaction effects between the compatibility of news crawls with gender and year in school, but not with other demographic factors including age, academic performance (GPA) and interest in news.

Ardac \& Unal (2008) point out that the length and characteristics of on-screen text play a less significant role than the memory capacities of the individual. Those with high memory capabilities were more likely to recall 
information than those with lower memory capacities, regardless of the features of the stimulus. Audience preferences and viewing habits are another factor. Bracken (2005, 2006) found that audience members who prefer high-definition formats retrieved more information from that format than they did from standard definition. Overall news interest is another factor. Ellis (2012) refers to the term "news junkie,” a person who regularly seeks out news. A “news junkie” may not be as susceptible to information overload as someone who is rarely exposed to news because they are comfortable with processing large amounts of information on a consistent basis and have the organizational categories to facilitate memory storage.

Attention, and where it is directed, is a related factor. Bradley (2007) uses the "negativity bias" to explain the correlation between arousing information and attention explaining that viewers tend to retain negative information over positive information. However, Lecheler et al. (2015) argue that the specific content of a message, regardless of its positive or negative connotation, is what elicits high emotional responses, which can in turn, dictate retention. Wise et al. (2008) consider both producer and viewer cuts and channel changes during a news program to have a significant effect on cognitive processing. Moments leading up to a change in stimulus, as controlled by the viewer, were found to produce less cognitive processing, while effort, arousal and encoding were increased when presented with the new stimulus (Lang et al., 2005). Lang's study found that memory was better for information between cuts that were related, rather than unrelated.

\subsection{Focus of the Study}

The focus of this study is to examine how crawls in local television newscasts impact the immediate recall and long-term retention of information. There are two perspectives to consider. The first is information overload and cognitive theory that contend additional and/or redundant information negatively impact information recall and retention. In contrast, the second perspective, the dual-coding hypotheses, argues that multiple forms of the message presented through synchronous channelsimproves recall and retention of information. News crawls add a compounding factor for both approaches as they can cover the same topic as the on-screen story (a reinforcing or compatible crawl) or they can pertain to a different news item (an incompatible crawl).

\section{Methodology and Analysis}

While news crawls have become increasingly common in local TV newscasts, the question of their effectiveness for immediate recall and long-term information retention remains largely unexplored. The news crawl is another level of information that must be perceived and stored to memory. According to information overload and the redundancy effect, adding the news crawl to the story increases the possibility of overload and reduced retention (Toffler, 1970, Mayer et al., 2008). In contrast, dual-coding argues that when exposed to multimedia information, it is encoded both visually and aurally (Paivio, 1971, 1986). Thus, the textual crawls would be an aid in retention. The content of a news crawl is another dimension. The crawl can reinforce the on-screen story being presented (reinforcing crawl) or it can be on a different topic (incompatible crawl). In this research, the focus is on whether the presence and content compatibility of the news crawl (reinforcing or incompatible) helps or hinders retention. In addition, crawl content is examined in the short and long-term to see if there are differences in retention. To explore these issues, six hypotheses were developed with three focusing on immediate recall and three on long-term information retention.

\subsection{Research Questions and Hypotheses}

The first set of hypotheses compares the impact of no crawls, reinforcing crawls and incompatible crawls on immediate and long-term retention. If the content of the crawl reinforces the on-screen story, will this improve retention or add to information overload and an inability to effectively store the information in both short-term and long-term memory? If the news crawl is about a different story and is incompatible with what is being presented on-screen, will this reduce retention? As longer-term memory benefits from dual-coding, will the added textual element of crawls, whether reinforcing or incompatible, still result in greater retention than having no crawls?

RQ1: Does the compatibility of a news crawl with the on-screen story impact short-term and long-term information recall?

H1: There is a difference in immediate recall based on crawl compatibility - no crawls, rein-forcing crawls or 
incompatible crawls.

H2: There is a difference in long-term retention based on crawl compatibility—no crawls, reinforcing crawls or incompatible crawls.

A related question is whether the information in a news crawl reinforces the retention and recall of other information that is in the on-screen story but not in the crawl itself. The presence of some elements of a story in textual form in the crawl might provide context and reduce the extent of information overload or it could add unnecessary redundancy that might hinder retention. For the long-term, will the added textual in-formation presented improve effective storing and recall of information from a story that is not reinforced in the text of the crawl?

To begin addressing this question, the next two hypotheses focus only on whether the information is in or not in the crawl regardless of whether the crawl supports or is incompatible with the on-screen story. Thus, it examines whether the presence of the textual element of the crawl itself is an aid in retention regard-less of what the on-screen story is presenting.

RQ2: Does the content of a news crawl, regardless of compatibility, reinforce the retention and recall of other information from a story that is not contained in the crawl?

H3: Regardless of crawl compatibility, immediate recall will be greater for information that is contained in both the on-screen story and the news crawl than only in the on-screen story.

H4: Regardless of crawl compatibility, long-term retention will be greater for information that is contained in both the on-screen story and the news crawl than only in the on-screen story.

For the final set of hypotheses, the focus is on the interaction of crawl compatibility and whether or not information in the on-screen story is also included in the crawl. The concept of "dual-coding" would suggest that information presented in the on-screen story and a reinforcing crawl would have the highest level of retention. In contrast, the redundancy effect indicates the added information of the crawls would impede retention. Incompatible crawls create a special issue. Information overload would suggest incompatible crawls would result in lower retention as the amount and diversity of information being presented simultaneously increases. For dual-coding, a question is whether retention is still enhanced if visual and textual information are not presented simultaneously. RQ3, focusing on crawl compatibility and whether the information is in the story only or in the story and crawl, will provide insights on this issue.

RQ3: Is there an interaction effect between crawl compatibility and whether information in the on-screen story is also included in the crawl?

H5: For immediate recall, there is an interaction effect between crawl compatibility and whether the on-screen information is also in the news crawl.

H6: For long-term retention, there is an interaction effect between crawl compatibility and whether the on-screen information is also in the news crawl.

\subsection{Experimental Method}

To investigate the impact of news crawls on the retention of information, a post hoc experimental design was used. Three groups of subject saw the same newscast with no crawls, reinforcing crawls or incompatible crawls. The study was conducted in spring of 2015 at a mid-sized public university in the Eastern United States. The university enrolls approximately 14,300 students with $85 \%$ being undergraduates.

For the stimulus, a 30-minute newscast with a strong local focus and no news crawls was used. The newscast was obtained from a station in a medium size television market, near the national median market size (The Nielsen Company, 2013). The station's location is outside the university's traditional recruitment and catchment area. As a result, the risk of prior exposure by the subjects to the geographic area, issues or local personalities was minimal. Three versions of the newscast were used. The control group saw the basic newscast without crawls. Treatment Group A saw the same newscast with crawls added that reinforced elements of the story currently being presented on-screen. Treatment Group B saw the same newscast and crawls but the crawls were rearranged so that the crawls were from a different story than the one on-screen (i.e., incompatible crawls). The news crawls used a headline approach (Tuggle, Carr, \& Huffman, 2004) focusing on the key information in the story. Print size, font and speed were set to reflect typical broadcast practice (Keefe-Feldman, 2007).

Subjects were recruited from a selection of introductory general education classes in Political Science, Geosciences and Communications. Of the 60 subjects, there were 29 females (48\%) and 31 males (52\%). Most of the participants were seniors (38\%) and juniors (28\%) with 20-years old (30\%) being the modal response. On a 
4.00-scale, $42 \%$ had a GPA in the 3.00 - 3.49 range and $38 \%$ in the $3.50-4.00$ range. Of the subjects, $32 \%$ said they did not watch local TV news and 35\% responded they watched it less than once a week. Only $7 \%$ watched local TV news four or more times per week. Finally, when asked about their interest in local news, 78\% said they were somewhat interested, 17\% said they were not interested and only 5\% responded very interested. Applicable statistical tests were conducted on each of these six variables (gender, college rank, age, GPA, frequency of watching local news and interest in local news). The tests showed there were no statistically significant differences in the composition of the three groups on any of these demographic variables.

Students who volunteered to participate received an online survey to collect demographic information and schedule their experimental session. Based on the demographics, subjects were assigned to the control or treatment groups to maintain a relatively even balance based on age, gender, and GPA. Upon reporting for the experiment, students watched their assigned version of the newscast then responded to a printed 18-question quiz on the content of the newscast. To test long-term retention, subjects received an email two weeks later asking them to respond to an online survey consisting of the same questions. The dependent variable of information retention was measured by the number of correct answers on the 18-question quiz. Each multiple choice question had four possible answers. There were two questions on the quiz for each on-screen story. One addressed information that was included in the text of the news crawl and the second question covered information in the on-screen story but not in the crawl.

In total, 60 students participated in the immediate recall portion of the experiment with 20 per group and 58 of the students completed the delayed retention portion two weeks later. In the long-term recall portion, one subject was lost from each of the treatment groups (reinforcing and incompatible crawls). All 20 subjects in the control group completed the entire study.

\subsection{Crawl Compatibility}

The first and second hypotheses focus on the impact of crawl compatibility (none, reinforcing or incompatible) on information retention. The scores for all 18 questions were examined across the three groups. For hypotheses $\mathrm{H} 1$ and H2, the Levene's test for homogeneity of variances was not significant and a one-way ANOVA was used for the analysis.

H1: There is a difference in immediate recall based on crawl compatibility - no crawls, reinforcing crawls or incompatible crawls.

The first hypothesis examines the impact of crawl compatibility on immediate recall (see Table 1). A one-way ANOVA showed there was a significance difference in the level of immediate recall across the three groups $(F=3.455$, $d f=2.57, p=0.038)$. The group seeing the reinforcing crawls performed the best $(\mathrm{M}=$ 12.600) with the no crawl, control group second $(\mathrm{M}=11.200)$ and the group seeing the incompatible crawls scoring the lowest $(M=10.450)$. A Tukey's HSD was run to see which differences between the three groups was significant. Tukey's HSD showed only a significant difference between the reinforcing and the incompatible crawl groups (Mdiff $=2.150, \mathrm{p}=0.032$ ).

H2: There is a difference in long-term retention based on crawl compatibility - no crawls, reinforcing crawls or incompatible crawls.

The second hypothesis focused on crawl compatibility and long-term recall. In this case, the dependent variable was the number of correct responses when the quiz was re-taken two weeks after seeing the newscasts. Two subjects, one in the reinforcing crawls and one in the incompatible crawls group, did not complete the long-term recall portion. The differences here were not significant $(F=1.761$, $\mathrm{df}=2.55, \mathrm{p}=0.181)$. Again, the group seeing the reinforcing crawls scored highest $(M=10.263$, SD = 1.727). However, the group viewing the incompatible crawls $(M=9.789, \mathrm{SD}=2.594)$ scored ahead of the no crawl group $(\mathrm{M}=9.000, \mathrm{SD}=1.938)$.

Table 1. Comparison of groups on immediate recall and long-term retention.

\begin{tabular}{cccc}
\hline Group & & Recall and Retention Levels \\
\cline { 2 - 3 } & Immediate Recall & Long-Term Retention & Change \\
\hline Control - No Crawls & $\mathrm{M}=11.200, \mathrm{SD}=2.462$ & $\mathrm{M}=9.000, \mathrm{SD}=1.938$ \\
Reinforcing Crawls & $\mathrm{M}=12.600, \mathrm{SD}=2.458$ & $\mathrm{M}=10.263, \mathrm{SD}=1.727$ & $\mathrm{M}=9.789, \mathrm{SD}=2.594$ \\
Incompatible Crawls & $\mathrm{M}=10.450, \mathrm{SD}=2.929$ & -2.337 & -0.661 \\
\hline
\end{tabular}


Of note is that the reinforcing crawls group (diff $=-2.337$ ) saw the largest drop in retention from the immediate to the long-term while the incompatible crawl group (diff $=-0.661$ ) saw the smallest decline (see Table 1 ). While the differences were not significant $(\mathrm{F}=2.169$, $\mathrm{df}=2.55, \mathrm{p}=0.124)$, a similar pattern is also seen with H5 and H6.

\subsection{Information Included in Crawl or in On-Screen Story Only}

The third and fourth hypotheses focus on differences in retention based on whether the on-screen information was also contained in the news crawl. For this portion of the study, the focus was only on the two treatments groups as the control group did not see the news crawls. The comparison is between scores on the nine questions that were addressed in the crawls and the nine questions that were only in the stories. An independent samples t-test was used for $\mathrm{H} 3$ and $\mathrm{H} 4$.

H3: Regardless of crawl compatibility, immediate recall will be greater for information that is contained in both the on-screen story and the news crawl than only in the on-screen story.

In the case of immediate recall, the differences were significant between the two groups $(t=3.779, \mathrm{df}=78, \mathrm{p}$ $<0.001)$. The scores for the questions included in the news crawls $(M=6.48, S D=1.519)$ were higher than for the questions that were only included in the on-screen stories $(M=5.05, S D=1.839)$. A related question is whether this difference holds when we look only at the group receiving the incompatible crawls or if the stronger performance of the reinforcing crawls group, as seen in H1, influenced the overall pattern. To test this, an independent samples t-test was run on the two sets of questions for the group seeing the incompatible crawls. In this case, the same significant pattern emerged $(\mathrm{t}=2.160, \mathrm{df}=38, \mathrm{p}=0.037)$. Even though the news crawls were incompatible with the on-screen story, the subjects scored higher on information contained in both the on-screen story and the crawl $(\mathrm{M}=5.80, \mathrm{SD}=1.436)$ than on information in the on-screen story only $(\mathrm{M}=4.65$, $\mathrm{SD}=1.899$ ). Despite the crawl being incompatible, it appears that it still aided in immediate recall.

H4: Regardless of crawl compatibility, long-term retention will be greater for information that is contained in both the on-screen story and the news crawl than only in the on-screen story.

This portion of the study explores the same issue as with $\mathrm{H} 3$ but the focus is on the two-week retention scores. As the Levene's test $(\mathrm{F}=4.871, \mathrm{p}=0.030)$ for homogeneity of variances was significant, equal variances were not assumed. Again, we find a significant difference $(\mathrm{t}=3.865, \mathrm{df}=67.549, \mathrm{p}<0.001)$ with subjects scoring better on questions that were included in the crawls $(\mathrm{M}=6.05, \mathrm{SD}=1.184)$ than on questions from the on-screen story only $(\mathrm{M}=4.79, \mathrm{SD}=1.630)$. As with $\mathrm{H3}$, a second analysis was done focusing only on the incompatible crawls group. Again, a significant difference was found $(t=2.038, \mathrm{df}=36, \mathrm{p}=0.049)$ with the questions covering information in the crawls and on-screen $(\mathrm{M}=5.79, \mathrm{SD}=1.398)$ showing a higher score than the on-screen only items $(\mathrm{M}=4.79,1.619)$. Thus, it appears the incompatible crawls did aid in retention.

\subsection{Interaction Effects}

Does the combination of crawl compatibility and whether information is in the on-screen story only or also included in the crawl, impact retention? To address this question, the focus is on the two treatment groups. The dependent variable is their retention of information between the questions for the on-screen only story and the questions that were also addressed in the crawls. Hypotheses H5 and H6 used the Univariate General Linear Model in SPSS 22 that adjusts for any problems with homogeneity of variances (Leech, et al., 2011; Norusis, 2008).

H5: For immediate recall, there is an interaction effect between crawl compatibility and whether the on-screen information is also in the news crawl.

The analysis indicated there was no significant interaction effect between crawl compatibility and the inclusion of information in the crawl on immediate recall $(\mathrm{F}=0.583, \mathrm{df}=1.76, \mathrm{p}=0.448)$. As seen in Table 2, the highest scores occur with the reinforcing crawls group for the information contained in the crawls $(M=7.15)$. It is also interesting to note that, while not significant, the incompatible crawl group had better recall on questions relating to information contained in the crawl $(M=5.80)$ than did the reinforcing group on questions not in the crawl $(M=5.45)$. This suggests that some degree of dual-coding or double-learning may be occurring even with incompatible crawls.

H6: For long-term retention, there is an interaction effect between crawl compatibility and whether the on-screen information is also in the news crawl. 
As with H5, no significant interaction effects were found across the compatibility groups and question types for long-term recall $(\mathrm{F}=0.642, \mathrm{df}=1.72, \mathrm{p}=0.426)$. The differences on the questions contained in the crawls between the reinforcing $(M=6.32)$ and the incompatible crawls $(M=5.79)$ were much less for the long-term recall $($ diff $=0.53)$ than for immediate recall $($ diff $=1.35)$. Table 2 also shows that for information not included in the crawl, there was no difference between the reinforcing crawls $(M=4.79)$ and the incompatible crawls ( $M$ $=4.79$ ) groups in long-term retention.

While not statistically significant, H5 and H6 show that in both immediate recall (diff $=1.70$ ) and long-term retention (diff $=1.53$ ), the reinforcing crawls group saw the greatest difference between story information in or not in the crawls (see Table 2). At the same time, the reinforcing crawl group also saw the largest drop between immediate recall and long-term retention for both information in the crawls (diff $=-0.83$ ) and not in the crawls (diff $=-0.66)$. In contrast, there was almost no drop between immediate and long-term scores for the incompatible crawls group for information contained in the crawls (diff $=-0.01$ ) and for information not in the crawls, the scores actually increased slightly $($ diff $=+0.14)$.

\section{Discussion}

This study examined the issue of news crawl compatibility and its impact on immediate recall and long-term retention of information. One perspective, from information overload and cognitive theory, is that the increased volume of information being presented would hinder recall and retention. In contrast, the dual-coding hypothesis suggests that the additional information assists with recall and improves long-term storage and retention. As with any experimental study, important caveats are the limitations of the sample and methodology. However, the results of this study suggest several interesting possibilities and areas for future research.

\section{Findings and Implications}

The findings from $\mathrm{H} 1$ suggest that for immediate recall, the addition of textual news crawls that reinforce the on-screen story was an aid. This supports the dual-coding hypothesis and double-learning elements (Paivio, 1969, 1971, 1986), the benefit of multiple channels (Brunye et al., 2008) and reflects the findings of Matsukawa et al. (2009) on reinforcing crawls. It also suggests that, at least at the level of content in the news crawls, the redundancy effect does not come into play. In contrast, the incompatible crawl group scored the lowest suggesting that incompatible crawls were a hindrance to immediate information retention. This is consistent with the observations of Keefe-Feldman (2007) and Hargittai et al. (2012). It also suggests that the incompatibility of information between the crawl and on-screen story may cross the threshold of information processing creating overload and inhibiting immediate recall (Joesphson \& Holmes 2006).

While the differences were not statistically significant for $\mathrm{H} 2$, the results are interesting and suggest an area for future study. While the reinforcing group scored the highest in long-term retention, the incompatible crawl group did better than the no crawl group. Unlike the negative impact on immediate recall, the textual element of the incompatible crawls may have facilitated the processing and encoding of information into long-term memory. Other studies have focused on concurrent processing and immediate recall (Matsukawa et al., 2009; Bruyne et al., 2008; van der Molen \& van der Voort, 2000). The findings for H1 and H2 suggest that the impact of incompatible crawls may differ for short-term recall compared to long-term retention. For the long-term, it may be

Table 2. Crawl compatibility and information in or not in the crawls.

\begin{tabular}{|c|c|c|c|c|}
\hline \multirow{2}{*}{$\begin{array}{c}\text { Recall and } \\
\text { Retention Type }\end{array}$} & \multirow[b]{2}{*}{ Crawl Compatibility } & \multicolumn{3}{|c|}{ Story Information } \\
\hline & & Included In Crawl & $\begin{array}{l}\text { Not Included } \\
\text { In Crawl }\end{array}$ & $\begin{array}{c}\text { Difference In or } \\
\text { Not In Crawl }\end{array}$ \\
\hline \multirow{3}{*}{ Immediate } & Reinforcing & $\mathrm{M}=7.15, \mathrm{SD}=1.309$ & $\mathrm{M}=5.45, \mathrm{SD}=1.731$ & -1.70 \\
\hline & Incompatible & $\mathrm{M}=5.80, \mathrm{SD}=1.436$ & $\mathrm{M}=4.65, \mathrm{SD}=1.899$ & -1.15 \\
\hline & Difference Reinforcing and Incompatible & 1.35 & 0.80 & \\
\hline \multirow{3}{*}{ Long-Term } & Reinforcing & $\mathrm{M}=6.32, \mathrm{SD}=0.885$ & $\mathrm{M}=4.79, \mathrm{SD}=1.686$ & -1.53 \\
\hline & Incompatible & $\mathrm{M}=5.79, \mathrm{SD}=1.398$ & $\mathrm{M}=4.79, \mathrm{SD}=1.619$ & -1.00 \\
\hline & Difference Reinforcing and Incompatible & 0.53 & 0.00 & \\
\hline \multirow{2}{*}{$\begin{array}{l}\text { Difference in Immediate } \\
\text { to Long-Term }\end{array}$} & Reinforcing & -0.83 & -0.66 & \\
\hline & Incompatible & -0.01 & 0.14 & \\
\hline
\end{tabular}


that the additional information of the crawl, even if not presented concurrently with the story, is an aid in retention.

$\mathrm{H} 3$ and $\mathrm{H} 4$ provide additional support for the concepts of dual-coding and double-learning within the scope of this study. When the news crawl contained information from the on-screen story, immediate recall and longterm retention were both greater than for information presented in the on-screen story only. This held even for the incompatible crawl group. For these two hypotheses, a follow-up comparison was done focusing only on the incompatible crawl group to be certain the stronger performance by the reinforcing crawl group was not influencing the overall results. The significant findings suggest that even when the visual/aural and textual information are not presented simultaneously, the textual information still contributes to enhanced immediate recall and long-term retention. One reason behind this phenomenon could be related to active learning theories. A person is more likely to recall information they cognitively process. The act of reading the information requires active viewing rather than passive viewing, causing the viewer to cognitively process and organize the text-based information (Clark \& Mayer, 2011). Similar to H2, this suggests that some form of dual-coding is occurring even when the multiple formats of the information are not presented simultaneously (Brunye et al, 2008; Mayer, 1997; Van der Molen \& Van der Voort, 1997, 1998, 2000).

The results for $\mathrm{H} 5$ and $\mathrm{H} 6$, while not statistically significant, suggest some interesting possibilities for future study. For the reinforcing crawls group, both immediate recall and long-term retention were higher for information contained in both the crawl and the on-screen story. However, the reinforcing crawl group saw the largest drop in information retention from the immediate to the long-term for both on-screen only items and on-screen plus the crawl. In contrast, the incompatible crawl group saw minimal decline for information in the crawl and the on-screen story and even a slight increase from immediate to long-term for information not in the crawl. This raises the possibility that simultaneous dual-coding achieves higher levels of immediate recall but a greater decline in long-term retention.

From Table 1, we can see a similar pattern of decline overall whether or not the on-screen story information is reinforced in the crawl. Overall, the incompatible crawls group started with a lower-level of immediate recall $(M=10.450)$ compared to the reinforcing crawls $(M=12.600)$ and the no crawls group $(M=11.200)$. However, the smallest decline from immediate to long-term occurred for the incompatible crawls group (diff $=-0.661$ ) with reinforcing (diff $=-2.337$ ) and no crawls (diff $=-2.200$ ) showing much larger declines. As existing studies focus primarily on immediate retention of information from news crawls, the issue of long-term retention is worthy of future study. LC4MP (Lang, 2000, 2004), with its focus on memory processing for long-term retention, provides some insights and possible factors for consideration in such a study.

\section{Conclusion}

This study offers some interesting initial conclusions as well as areas for future study. H3 and H4 provide support for the dual-coding hypothesis as the immediate recall and long-term retention of information is greater for items included in the crawls. This suggests that while synchronous presentation produces higher levels, the presence of incompatible crawls also does improve recall and retention. However, reinforcing crawls show higher recall, as seen in H1, indicating that synchronous presentation has an advantage in immediate recall. Focusing on longer-term retention, $\mathrm{H} 2, \mathrm{H} 5$ and $\mathrm{H} 6$, while not statistically significant, provide some items for future study. These suggest that the impact of reinforcing crawls produces higher initial recall but faster decline over time than incompatible crawls. Future studies focusing on reinforcing and incompatible crawls would help provide added insight into this issue and the possibility dual-coding that is not simultaneous is actually occurring and supporting long-term retention.

\section{Acknowledgements}

The authors would like to thank the Center for Media Production and Research at Indiana University of Pennsylvania for their assistance with this research project.

\section{References}

Ardac, D., \& Unal, S. (2008). Does the Amount of On-Screen Text Influence Student Learning from a Multimedia-Based Instructional Unit? Instructional Science, 36, 75-88.http://dx.doi.org/10.1007/s11251-007-9035-4

Bergen, L., Grimes, T., \& Potter, D. (2005). How Attention Partitions Itself during Simultaneous Message Presentations. 
Human Communication Research, 31, 311-336.http://dx.doi.org/10.1111/j.1468-2958.2005.tb00874.x

Bracken, C. C. (2006). Perceived Source Credibility of Local Television News: The Impact of Television Form and Presence. Journal of Broadcasting \& Electronic Media, 50, 723-741.http://dx.doi.org/10.1207/s15506878jobem5004_9

Bracken, C. C. (2005). Presence and Image Quality: The Case of High Definition Television. Media Psychology, 7, $191-205$. http://dx.doi.org/10.1207/S1532785XMEP0702_4

Bradley, S. (2007). Dynamic, Embodied, Limited-Capacity Attention and Memory: Modeling Cognitive Processing of Mediated Stimuli. Media Psychology, 9, 211-239. http://dx.doi.org/10.1080/15213260709336810

Brunye, T., Taylor, H., \& Rapp, D. (2008). Repetition and Dual Coding in Procedural Multimedia Presentations. Applied Cognitive Psychology, 22, 877-895. http://dx.doi.org/10.1002/acp.1396

Chandler, P., \& Sweller, J. (1991). Cognitive Load Theory and the Format of Instruction. Cognitive and Instruction, 8, 293332. http://dx.doi.org/10.1207/s1532690xci0804_2

Clark, R. C., \& Mayer, R. E. (2011). E-Learning and the Science of Instruction: Proven Guidelines for Consumers and Designers of Multimedia Learning. San Fransisco, CA: Pfeiffer. http://dx.doi.org/10.1002/9781118255971

Consoli, J. (2009). Keeping the News Crawl Running during Ad Breaks. The New York Times. http://www.nytimes.com/2009/04/30/business/media/30adco.html? r=0

Ellis, J. (2012). How We Read, Not What We Read, May Be Contributing to Our Information Overload. Neiman Lab. http://www.niemanlab.org/2012/11/how-we-read-not-what-we-read-may-be-contributing-to-our-information-overload/

Fulton, L. (2014). Information Retention of Audio Based Public Service Announcements: The Impact of Messages Created Using Different Production Methods. Doctoral Dissertation. Indiana, PA: Indiana University of Pennsylvania.

Grabe, M. E., Zhou, S., \& Bolls, P. D. (2000). Packaging Television News: The Effects of Tabloid on Information Processing and Evaluative Responses. Journal of Broadcasting and Electronic Media, 44, 581-598.

http://dx.doi.org/10.1207/s15506878jobem4404_4

Grabe, M. E., Lang, A., \& Zhao, X. (2003). News Content and Form. Implications for Memory and Audience Evaluations. Communication Research, 30, 387-413. http://dx.doi.org/10.1177/0093650203253368

Grimes, T. (1990). Encoding TV News Messages into Memory. Journalism Quarterly, 67, 757-766. http://dx.doi.org/10.1177/107769909006700430

Hargittai, E., Neuman, W. R., \& Curry, O. (2012). Taming the Information Tide: Perceptions of Information Overload in the American Home. The Information Society, 28, 161-173. http://dx.doi.org/10.1080/01972243.2012.669450

Hinds, L. (1995). Broadcasting the Local News: The Early Years of Pittsburgh's KDAK-TV. University Park, PA: Pennsylvania State University Press. http://dx.doi.org/10.1086/208981

Jacoby, J. (1984). Perspectives on Information Overload. Journal of Consumer Research, 10, 432-435. http://dx.doi.org/10.1086/208981

Joesphson, S., \& Holmes, M. (2006). Clutter or Content? How On-Screen Enhancements Affect How TV Viewers Scan and What They Learn. Proceedings of the 2006 Symposium on Eye Tracking Research \& Applications, San Diego, 27-29 March 2006, 155-162. http://dx.doi.org/10.1145/1117309.1117361

Kalyuga, S., Chandler, P., \& Sweller, J. (1999). Managing Split-Attention and Redundancy in Multimedia Instruction. Applied Cognitive Psychology, 13, 351-371. http://dx.doi.org/10.1002/(SICI)1099-0720(199908)13:4<351::AID-ACP589>3.0.CO;2-6

Kalyuga, S., Chandler, P., \& Sweller, J. (2004). When Redundant On-Screen Text in Multimedia Technical Instruction Can Interfere with Learning. Human Factors: The Journal of the Human Factors and Ergonomics Society, 46, 567-581. http://dx.doi.org/10.1518/hfes.46.3.567.50405

Keefe-Feldman, M. (2007). The Cable News Ticker, View Comprehension, and Information Overload: Less Is More. Master's Thesis, Washington DC: Georgetown University.

Klinenberg, E., \& Krause, M. (2005). Public Service and the Transformations of the Journalistic Field: Local Reporting in US News Media 1890-2000. Philadelphia, PA: The American Sociological Association. http://dx.doi.org/10.1177/0163443710385502

Lang, A., Bolls, P. D., Potter, R., \& Kawahara, K. (1999). The Effects of Production Pacing and Arousing Content on the Information Processing of Television Messages. Journal of Broadcasting \& Electronic Media, 43, 451-457. http://dx.doi.org/10.1080/08838159909364504

Lang, A. (2000). The Limited Capacity Model of Mediated Message Processing. Journal of Communication, 50, 46-70. http://dx.doi.org/10.1111/j.1460-2466.2000.tb02833.x

Lang, A., Schwartz, N., Yongkuk, C., \& Seungwhan, L. (2004). Processing Substance Abuse Messages: Production Pacing, Arousing Content, and Age. Journal of Broadcasting \& Electronic Media, 48, 61-88. 
http://dx.doi.org/10.1207/s15506878jobem4801_4

Lang, A. (2006). Using the Limited Capacity Model of Motivated Mediated Message Processing to Design Effective Cancer Communication Messages. Journal of Communication, 56, 57-80. http://dx.doi.org/10.1111/j.1460-2466.2006.00283.X

Lang, A., Shin, M., Bradley, S. D., Wang, Z., Lee, S., \& Potter, D. (2005). Wait! Don’t Turn That Dial! More Exciting to Come! The Effects of Story Length and Production Pacing in Local Television News on Channel Changing Behaviour and Information Processing in a Free Choice Environment. Journal of Broadcasting \& Electronic Media, 40, 460-477. http://dx.doi.org/10.1080/08838159609364369

Lindsay, P., \& Norman, D. (1977). Human Information Processing: An Introduction to Psychology (2nd ed.). New York: Academic Press. http://www.phon.ucl.ac.uk/courses/spsci/audper/SDT\%20Lindsay\%20\&\%20Norman\%20App\%20B.pdf

Lecheler, S., Bos, L., \& Vliegenthart, R. (2015). The Mediating Role of Emotions: News Framing Effects on Opinions about Immigration. Journalism and Mass Communication Quarterly, 92, 812-838. http://dx.doi.org/10.1177/1077699015596338

Matsukawa, R., Miyata, Y., \& Ueda, S. (2009). Information Redundancy Effect on Watching TV News: Analysis of Eye Tracking Data and Examination of the Contents. Library and Information Science, 62, 193-205.

Mayer, R. E. (1997). Multimedia Learning: Are We Asking the Right Questions? Educational Psychologist, 32, 1-19. http://dx.doi.org/10.1207/s15326985ep3201_1

Mayer, R. E., Heiser, J., \& Lonn, S. (2001). Cognitive Constraints on Multimedia Learning: When Presenting More Material Results in Less Understanding. Journal of Educational Psychology, 93, 187-198. http://dx.doi.org/10.1037/0022-0663.93.1.187

Mayer, R. E. (2005). Cognitive Theory of Multimedia Learning. In R. E. Mayer (Ed.), The Cambridge Handbook of Multimedia Learning (pp. 31-48). New York: Cambridge University Press. http://dx.doi.org/10.1017/cbo9780511816819.004

Mayer, R. E., Griffith, E., Jurkowitz, I. T. N., \& Rothman, D. (2008). Increased Interestingness of Extraneous Details in a Multimedia Science Presentation Leads to Decreased Learning. Journal of Experimental Psychology: Applied, 14, 329339. http://dx.doi.org/10.1037/a0013835

Mitchell, A., Olmstead, K., Jurkowitz, M., \& Enda, J. (2013). How Americans Get TV News at Home. Washington DC: Pew Research Center.

Paivio, A. (1969). Mental Imagery in Associative Learning and Memory. Psychological Review, 61, 179-211. http://dx.doi.org/10.1037/h0027272

Paivio, A. (1971). Imagery and Verbal Processes. New York: Holt.

Paivio, A. (1986, 1990). Mental Representations: A Dual Coding Approach. New York: Oxford University Press. http://dx.doi.org/10.1093/acprof:oso/9780195066661.001.0001

Pavolik, B. (2015). News Crawls and Audience Retention: A Test of Information Overload in Local Television News Programming. Doctoral Dissertation, Indiana, PA: Indiana University of Pennsylvania.

Poniewozik, J. (2010). The Tick, Tick, Tick of the Times. Time Magazine Online. http://content.time.com/time/specials/packages/article/0,28804,2032304 2032745 2032850,00.html

Qihao, J., Sypher, U., \& Ha, L. (2014). The Role of News Media Use and Demographic Characteristics in the Prediction of Information Overload. International Journal of Communication, 8, 699-714.

Rodrigues, R., Veloso, A., \& Mealha, O. (2012). A Television News Graphic Layout Analysis Method Using Eye Tracking. Proceedings of the 16th International Conference on Information Visualisation, Montpellier, 11-13 July 2012, $357-362$.

Romano, A. (2002). Ticker Embedded in News. Broadcasting \& Cable, 132, 26.

Ruiji, L. (2012). The Development on Multimedia Teaching Resources Based on Information Processing Theory. International Journal of Advancements in Computing Technology, 4, 58-64. http://dx.doi.org/10.4156/ijact.vol4.issue2.8

Schweppe, J., \& Rummber, R. (2014). Attention, Working Memory, and Long-Term Memory in Multimedia Learning: An Integrated Perspective Based on Process Models of Working Memory. Educational Psychology Review, 26, 285-306. http://dx.doi.org/10.1007/s10648-013-9242-2

Strauss, R. (2002). Crawls Speed News to Antsy TV Viewers. Orlando Sentinel. http://articles.orlandosentinel.com/2002-01-04/lifestyle/0201030384_1_crawls-huang-viewers/2

Sweller, J., van Merrienboerm, J., \& Paas, F. (1998). Cognitive Architecture and Instructional Design. Educational Psychology Review, 10, 251-296. http://dx.doi.org/10.1023/A:1022193728205

The Nielsen Company (2013). Local Television Market Universe Estimates Comparisons of 2012-13 and 2013-14 Market Ranks. http://www.nielsen.com/content/dam/corporate/us/en/public\%20factsheets/tv/2012-2013\%20DMA\%20Ranks.pdf

Toffler, A. (1970). Future Shock. New York: Random House.

Torcasio, S., \& Sweller, J. (2009). The Use of Illustrations When Learning to Read: A Cognitive Load Theory Approach. Applied Cognitive Psychology, 24, 659-672. http://dx.doi.org/10.1002/acp.1577 
Van der Molen, W., \& Van der Voort, T. (2000). The Impact of Television, Print, and Audio on Children’s Recall of the News: A Study of Three Alternative Explanations for the Dual-Coding Hypothesis. Human Communication Research, 26, 3-26. http://dx.doi.org/10.1111/j.1468-2958.2000.tb00747.x

Weber, R., Westcott-Baker, A., \& Anderson, G. (2013). A Multilevel Analysis of Anti-Marijuana Public Service Announcement Effectiveness. Communication Monographs, 80, 302-330. http://dx.doi.org/10.1080/03637751.2013.788254

Williamson, J., \& Eaker, P. E. (2012). The Information Overload Scale. Proceedings of the 75th Annual Conference of the American Society for Information Science \& Technology, Baltimore, 26-30 October 2012, Page.

Wise, K., Lee, S., Lang, A., Fox, J., \& Grabe, M. (2008). Responding to Change on TV: How Viewer-Controlled Changes in Content Differ from Programmed Changes in Content. Journal of Broadcasting \& Electronic Media, 52, 182-199. http://dx.doi.org/10.1080/08838150801991773

Woodstock, L. (2014). The News-Democracy Narrative and the Unexpected Benefits of Limited News Consumption: The Case of News Resisters. Journalism, 15, 834-849. http://dx.doi.org/10.1177/1464884913504260 